W. Molé: Ein Problem der byzantinischen Kunstgeschichte in Polen

EIN PROBLEM

\title{
DER BYZANTINISCHEN KUNSTGESCHICHTE IN POLEN
}

\section{WOJSŁAW MOLÉ / KRAKÓW}

Die Geschichte Polens hat das Land seit seiner Christianisierung so eng an die abendländische Kulturentwicklung angeschlossen, daB die Problemstellung Polen-Byzanz in der Kunstgeschichte im ersten Augenblick wenigstens überflüssig erscheint. Und doch zeigt es sich bei näherem Zusehen, daB dem nicht so ist. Freilich handelt es sich dabei um keine rein byzantinischen Denkmälergruppen, die von entscheidendem Einfluß auf die Gestaltung der künstlerischen Physiognomie des Landes zeugten, - nichtsdestoweniger aber erwachsen aus der Erforschung der mittelalterlichen und späteren Kunst Polens Probleme, deren Lösung für die Frage der Beziehungen zwischen dem slavischen Osten Europas und Byzanz von weittragender Bedeutung sein können.

Schon allein aus der geographischen Lage Polens ergeben sich für die Kunstgeschichte sehr verschiedenartige Fragen, welche teils die Beziehungen des ursprünglichen, rein polnischen Gebietes zur byzantinischen Kunst, teils die Gestaltung dieser Beziehungen in den östlichen, ethnisch, religiös und kulturell gemischten Grenzgebieten betreffen und schließlich die Vermittlerrolle Polens zwischen der östlichen und westlichen Kunstentwicklung beleuchten.

Die Denkmäler reichen vom X. bis zum XVIII. Jahrh., doch sind sie örtlich und zeitlich verschieden und lückenhaft verteilt. Eine Zeitlang hat es geschienen, als ob das älteste erhaltene christliche Baudenkmal Polens, die sog. Rotunde der hl. Felix und Adauctus auf dem Wawelberge in Krakau, welche vielleicht aus dem X. Jahrh. stammt, auch in dieses Gebiet gehörte oder wenigstens irgendwie mit dem Osten zusammenhänge. U. a. hat Strzygowski bald nach ihrer Entdeckung und in seinem Werke über Armenien auf Ähnlichkeiten mit armenischer Architektur hingewiesen. Jetzt bringt er sie in seiner „Altslavischen Kunst" - sowie auch die altkroatischen Kirchen Dalmatiens - mit altslavischer Kunst in Verbindung und sieht ihre Vorbilder im hölzernen Blockbau Osteuropas. Ohne auf diese Hypothese, deren Begründung ja höchst fraglich ist, näher einzugehen, wird man, ohne dabei von Blockbau und altslavischer Kunst zu sprechen, Strzygowski insofern recht geben müssen, daß wir es mit einem Bau zu tun haben, dessen nächste Verwandte auf norddeutschem und baltischem Gebiet zu suchen sind. Jedenfalls scheidet dieses Denkmal aus unserer Fragestellung aus.

In der Piastenzeit fehlte es nicht an dynastischen Verbindungen mit dem weiteren slavischen Osten, doch gibt es auf engerem polni- 
schem Gebiet keine Denkmäler, deren östlicher Ursprung ganz sicher wäre. Erst im XIV. Jahrh. wird es auf einmal anders, und auf diese Frage möchte ich kurz hinweisen.

Unter Ladislaus Jagello sowie auch unter seinen nächsten Nachfolgern sehen wir eine Reihe von großen „ruthenischen" Wandgemäldezyklen entstehen, von denen sich drei noch erhalten haben: im Chor der Domkirche zu Sandomierz, in Lublin und in der hl. Kreuzkapelle der Wawelkathedrale; Fragmente eines vierten Zyklus sind vor kurzem in Wiślica an den Tag gekommen; andere, z. B. in Koprzywnica, sind von der späteren Tünchenbedeckung noch nicht befreit worden (auch in Sandomierz sind bisher eigentlich nur drei gotische Gewölbefelder freigelegt und dürften die übrigen Felder noch Überraschungen bieten). Von anderen Freskenzyklen berichten schriftliche Quellen. Freilich muß im vorhinein festgestellt werden, daß es sich bei diesen Malereien um importierte Hofkunst handelt, die von den Jagellonenkönigen begünstigt und als gleichwertig neben der gotischen Kunst gepflegt wurde; das beeinträchtigt aber doch nicht ihre Bedeutung. Denn woher stammt diese Kunst? Man hatte von der Herkunft der Jagellonen auch auf die Herkunft dieser Malerei geschlossen und sie aus RussischLitauen bzw. WeißruBland herleiten wollen. Wenn dem wirklich so wäre, so wäre damit eine große Lücke in unserer Kenntnis der Kunstentwicklung der westrussischen Gebiete ausgefüllt. Nach neueren Untersuchungen, deren Veröffentlichung ich nicht vorgreifen will, zeigt es sich aber, daß stilistische und ikonographische Gründe gegen eine solche Annahme sprechen; alles, was sich heute sagen läßt, ist die sichere Feststellung, daß die Maler dieser Wandgemälde aus einem in Rotrußland gelegenen Kunstzentrum (Lemberg?) herkommen, welches seine Anregungen wesentlich dem Balkan entlehnt, was ja schließlich auch ganz natürlich ist, wenn man die damaligen politischen Beziehungen Polens zur Moldawei und die nach dem Orient führenden Verkehrswege in Betracht zieht. Und schon diese Feststellung allein ist wichtig, denn einerseits ist damit ein russisch-byzantinisches Kunstzentrum wiedergewonnen, von dessen Malerei wir aus dieser Zeit sonst. keine Spuren besitzen, anderseits aber zeigt es sich, daß sich die kulturellen Beziehungen Polens zum Balkan nicht nur auf das ethnographische Gebiet beschränken, sondern auch auf die monumentale Kunst herübergreifen. Diese Beziehungen sind freilich nicht einseitig, denn Polens Anteil an der Kunstentwicklung einiger rumänischen Gebiete unterliegen wohl keinem Zweifel. Nur sind diese Probleme von der polnischen Kunstgeschichte bisher auffallenderweise nicht genügend und entsprechend berücksichtigt worden. 